\title{
-Original-
}

\section{Activation and Penetration In Vitro of Pig Oocytes Treated with Calcium Ionophore}

\author{
Atsushi ASANO ${ }^{1)}$ and Koji NIWA ${ }^{1,2)}$ \\ 1) The Graduate School of Natural Science and Technology, Okayama University, Okayama \\ 700-8530, and ${ }^{2)}$ Faculty of Agriculture, Okayama University, Okayama 700-8530, Japan
}

\begin{abstract}
The present study examined the effects of pre-treatment of pig oocytes with different concentrations $(0-50 \mu \mathrm{M})$ of calcium ionophore A23187 (CaA) on their activation, development and penetration in vitro. Although untreated oocytes were not activated and did not cleave in culture, high proportions of treated oocytes did so and $20 \%$ of oocytes developed to the blastocyst stage when treated with $6.25 \mu \mathrm{M} \mathrm{CaA}$ for $2 \mathrm{~min}$. However, these proportions were reduced in a concentrationdependent manner. When inseminated in vitro with $1 \times 10^{6}$ spermatozoa $/ \mathrm{ml}$, the penetration rate of oocytes treated with $6.25 \mu \mathrm{M} \mathrm{CaA}$ was similar to that of untreated oocytes. However, fewer oocytes treated with 12.5 and $50 \mu \mathrm{M} \mathrm{CaA}$ were penetrated than untreated oocytes. On the other hand, the proportion of monospermy of oocytes treated with $6.25 \mu \mathrm{M} \mathrm{CaA}$ was higher than the values in oocytes not treated or treated with $50 \mu \mathrm{M} \mathrm{CaA}$. The time required for zona dissolution of oocytes treated with 6.25 and $12.5 \mu \mathrm{M} \mathrm{CaA}$ was not different from that in untreated oocytes, but oocytes treated with $50 \mu \mathrm{M}$ $\mathrm{CaA}$ required a longer time than untreated oocytes, indicating that zona solubility by protease does not reflect penetrability of oocytes in vitro. When oocytes were inseminated with different concentrations $\left(1-10 \times 10^{6}\right.$ cells $\left./ \mathrm{ml}\right)$ of spermatozoa, the highest penetration rate was observed at $1 \times$ $10^{6}$ cells $/ \mathrm{ml}$ in untreated oocytes and a similar result was obtained in oocytes treated with $6.25 \mu \mathrm{M}$ $\mathrm{CaA}$. There was no difference in the rate of monospermy in untreated oocytes among different concentrations of spermatozoa, but in treated oocytes, higher proportions of monospermy were observed at $0.5-5 \times 10^{6}$ than $10 \times 10^{6}$ cells $/ \mathrm{ml}$. At $1 \times 10^{6}$ cells $/ \mathrm{ml}$, the proportion of monospermy was higher in treated than untreated oocytes. These results suggest that pre-treatment of pig oocytes with $6.25 \mu \mathrm{M} \mathrm{CaA}$, an appropriate concentration, inhibits polyspermic penetration in vitro when insemination occurs with spermatozoa at a concentration of $1 \times 10^{6}$ cells $/ \mathrm{ml}$.
\end{abstract}

Key words: Calcium ionophore A23187, In vitro fertilization (IVF), Monospermy, Pig, Polyspermy

(J. Reprod. Dev. 50: 77-85, 2004)

A series of repetitious and transient increases in the concentration of the intracellular free calcium ion $\left(\left[\mathrm{Ca}^{2+}\right] \mathrm{i}\right)$ is induced in activated oocytes after fusion with spermatozoa in many mammals [1-4], including pigs [5, 6]. One of the important roles of the $\left[\mathrm{Ca}^{2+}\right] \mathrm{i}$ increase in penetrated oocytes is to induce cortical granule (CG) exocytosis, which is responsible for the zona reaction that participates in the block to polyspermy in most mammals [7-9].

Accepted for publication: October 28, 2003

Correspondence: K. Niwa (e-mail: kniwa@cc.okayama-u.ac.jp)
The zona reaction and the block to polyspermic penetration are easily induced in pig oocytes under normal physiological conditions [10], but a high incidence of polyspermy in pig oocytes matured and penetrated in vitro has been reported by many researchers [11-13]. Although pig oocytes matured both in vivo and in vitro release CG contents upon sperm penetration, oocytes penetrated in vivo release CG contents more quickly than those penetrated in vitro [14]. Furthermore, CG contents disperse in the perivitelline space of in vivo 
penetrated oocytes, but not in vitro penetrated oocytes, after CG exocytosis [14-16]. Delayed and partial CG exocytosis has also been reported in pig oocytes matured and inseminated in vitro [17]. On the other hand, a high concentration of spermatozoa is generally used for in vitro fertilization (IVF) and this condition may be one of the reasons for the polyspermic penetration that occurs even in fertilization in vivo in pigs [10]. Under such conditions, spermatozoa may continue to penetrate oocytes before the oocytes establish a complete zona reaction [18]. Although it is not known how this phenomenon can be prevented in vitro, oviductal secretions [16, 19, 20], epithelial cells [21,22], exogenous hyaluronan [23], and fertilization promoting peptide or adenosine [24] have all been suggested to participate in the prevention of polyspermy in pig oocytes.

Calcium ionophore A23187 (CaA) is one of the most effective chemical stimulators for the activation of oocytes and has been widely used in many animals. In oocytes activated by $\mathrm{CaA},\left[\mathrm{Ca}^{2+}\right] \mathrm{i}$ increase is induced and becomes a trigger for CG exocytosis $[5,9]$. Although CG exocytosis is responsible for a zona reaction, only a partial block of sperm penetration is observed in mouse [25] and rat [26] oocytes treated with CaA. This may be due to incomplete CG exocytosis in CaA-treated oocytes as observed in pig oocytes [14, 17, 27]. The CaA-induced activation and CG exocytosis of oocytes may be dose-dependent [27-29]. A dosedependent activation has been observed in modified Tris-buffered medium (mTBM) [27], but not in phosphate buffered saline (PBS) [30]. Furthermore, the activation rate of oocytes treated with a fixed dose of $\mathrm{CaA}$ did not increase with increased treatment time [31,32]. On the other hand, sperm penetration in vitro of pig oocytes was dose-dependently inhibited by pre-treatment with $\mathrm{CaA}$, with reduced rates of polyspermy [27]. It has been shown that this inhibition did not occur but the rate of monospermy increased when maturing pig oocytes (matured for $33 \mathrm{~h}$ in culture) were treated with lower concentrations of $\mathrm{CaA}$ in medium with or without fetal bovine serum (FBS) [32]. These results indicate that if pig oocytes fully matured for $44 \mathrm{~h}$ in culture could be activated with lower concentrations of $\mathrm{CaA}$ synchronously with sperm penetration, it might be possible to increase the incidence of monospermy without reducing the penetration rate in vitro. The present study was designed to investigate this possibility using pig oocytes matured for $44 \mathrm{~h}$ in culture examining: 1) the rates of activation, early development and penetration in vitro, and zona dissolution of oocytes treated with different concentrations of $\mathrm{CaA}$, and 2) the effects of sperm concentrations on monospermic penetration in vitro of oocytes treated with a fixed concentration of $\mathrm{CaA}$.

\section{Materials and Methods}

\section{Media}

The basic medium used for the manipulation of oocytes and spermatozoa was tissue culture medium 199 (TCM-199; with Earle's salts; Gibco, Grand Island, NY, USA) supplemented with 3.05 mM D-glucose, $0.91 \mathrm{mM}$ sodium pyruvate, $75 \mu \mathrm{g} /$ $\mathrm{ml}$ potassium penicillin $\mathrm{G}$, and $50 \mu \mathrm{g} / \mathrm{ml}$ streptomycin sulfate. The medium was designated basic TCM-199 (bTCM-199). The medium used for in vitro maturation (IVM) of oocytes was bTCM-199 ( $\mathrm{pH}$ 7.4) supplemented with $10 \%$ (v/v) pig follicular fluid (pFF), $0.57 \mathrm{mM} \mathrm{L}$-cysteine (Sigma Aldrich Chemical Co., St. Louis, MO, USA), 10 IU/ $\mathrm{ml}$ equine chorionic gonadotropin, and $10 \mathrm{IU} / \mathrm{ml}$ human chorionic gonadotropin. The pFF was withdrawn into a $10-\mathrm{ml}$ disposable syringe through an 18-gauge needle from superficial follicles (2-5 $\mathrm{mm}$ in diameter) on maturing pig ovaries. The $\mathrm{pFF}$ was centrifuged at $1,500 \times \mathrm{g}$ for $15 \mathrm{~min}$ at room temperature (24-25 C) to remove any cells or debris, and the supernatant was stored at $-20 \mathrm{C}$ until used [33]. The medium used for IVF of oocytes was bTCM-199 (pH 7.8) supplemented with $2.92 \mathrm{mM}$ hemi-calcium lactate, $2.5 \mathrm{mM}$ caffeine-sodium benzoate (Sigma), and $2 \mathrm{mg} / \mathrm{ml}$ BSA (A-7888; Fraction V, Sigma). The IVF medium was essentially the same as TCM-199B used by Wang et al. [34], except that $2 \mathrm{mg} / \mathrm{ml}$ BSA was substituted for FBS.

\section{Preparation of oocytes}

Ovaries isolated from maturing gilts at a local slaughterhouse were transported to the laboratory within $1-1.5 \mathrm{~h}$ of slaughter in $0.9 \%(\mathrm{w} / \mathrm{v}) \mathrm{NaCl}$ solution containing $75 \mu \mathrm{g} / \mathrm{ml}$ potassium penicillin $\mathrm{G}$ and $50 \mu \mathrm{g} / \mathrm{ml}$ streptomycin sulphate at 37-39 C. Cumulus-oocyte complexes (COCs) were aspirated from antral follicles ( $2-5 \mathrm{~mm}$ in diameter) through an 18-gauge needle into a $10-\mathrm{ml}$ disposable syringe 
and washed three times with modified HEPESbuffered Tyrode's medium containing $0.1 \%(\mathrm{w} / \mathrm{v})$ polyvinylalcohol (HEPES-TL-PVA). The complexes with uniform ooplasm and a compact cumulus cell mass were washed again three times with IVM medium. Fifty COCs were transferred to $500 \mu \mathrm{l}$ of the same medium, which had previously been covered with warm paraffin oil (Nacalai Tesque Inc., Kyoto, Japan) in a four-well culture plate (Nunc, Roskilde, Denmark) and equilibrated in an atmosphere of $5 \% \mathrm{CO}_{2}$ in air for a minimum of $3 \mathrm{~h}$, and were cultured for $44 \mathrm{~h}$ at $39 \mathrm{C}$ under the same atmospheric conditions. After culture, oocytes were freed from cumulus cells by repeated passage through a fine pipette in IVM medium containing $0.1 \%$ hyaluronidase from bovine testes (Sigma). The denuded oocytes were washed three times with caffeine-free IVF medium before treatment with Ca-ionophore A23187 (CaA; C-7522, Sigma).

\section{Treatment of oocytes with $\mathrm{CaA}$}

The $\mathrm{CaA}$ was dissolved in dimethyl sulfoxide (DMSO) at a concentration of $5 \mathrm{mM}$, and the stock solution was kept at $-32 \mathrm{C}$ until used. The stock solution $(5 \mu \mathrm{l})$ without dilution and diluted two, four, and eight times with caffeine-free IVF medium was added to $495 \mu \mathrm{l}$ of the same medium covered with paraffin oil in a four-well culture plate (Nunc) to give 50, 25, 12.5 and $6.25 \mu \mathrm{M} \mathrm{CaA}$, respectively. For the control $(0 \mu \mathrm{M} \mathrm{CaA})$, no stock solution was added. The maximal concentration of DMSO introduced into the medium was $1.0 \%(\mathrm{v} / \mathrm{v})$ in the presence of $50 \mu \mathrm{M} \mathrm{CaA}$. The four-well culture plate was kept on a warm plate at $39 \mathrm{C}$ and 20-30 denuded oocytes were introduced into each drop of medium for treatment with different concentrations of $\mathrm{CaA}$ for $2 \mathrm{~min}$.

\section{Assessment of activation and development of $\mathrm{CaA}$ treated oocytes}

Oocytes treated or not treated with $\mathrm{CaA}$ were washed six times with IVF medium and transferred into $50 \mu \mathrm{l}$ of the same medium covered with paraffin oil in a culture dish $(\varnothing 35 \times 10 \mathrm{~mm}$, Becton and Dickinson, Franklin Lakes, NJ, USA). At $12 \mathrm{~h}$ after the start of culture at $39 \mathrm{C}$ in $5 \% \mathrm{CO}_{2}$ in air, oocytes were fixed with $25 \%(\mathrm{v} / \mathrm{v})$ acetic acid in ethanol, stained with $1 \%(\mathrm{w} / \mathrm{v})$ orcein, and examined under a phase-contrast microscope at magnifications of $\times 200$ and $\times 400$ for activation.
Oocytes with one female pronucleus and second polar body or with two pronuclei were considered as activated. For the development of oocytes, they were first cultured for $6 \mathrm{~h}$ in IVF medium containing $2.5 \mu \mathrm{g} / \mathrm{ml}$ cytochalasin B (CB; C-6762, Sigma) to induce activation producing two female pronuclei and then for $6 \mathrm{~h}$ in the medium without CB. After this two-step culture, oocytes were washed three times with NCSU-23 medium [35] and were further cultured in the same medium in $5 \% \mathrm{CO}_{2}$ in air at $39 \mathrm{C}$. Oocytes were examined for cleavage and development to blastocysts at 36 and $156 \mathrm{~h}$ after the start of the final culture, respectively, under a stereoscopic microscope at $\times 100$.

\section{Assessment of solubility of zona pellucida (ZP) of $\mathrm{CaA}$ treated oocytes}

Solubility of the ZP was assessed as described previously [16]. Briefly, oocytes treated with $\mathrm{CaA}$ were cultured for $4.5 \mathrm{~h}$ in IVF medium and then washed six times with HEPES-TL-PVA. Eight or ten oocytes were transferred into $500 \mu \mathrm{l}$ of HEPESTL-PVA containing $0.1 \%(\mathrm{w} / \mathrm{v})$ protease $(\mathrm{P}-6911$; Sigma) and were continuously observed for dissolution of the $\mathrm{ZP}$ at room temperature under a stereoscopic microscope at $\times 100$. The time required for dissolution of the $\mathrm{ZP}$ in $50 \%$ of the oocytes was designated as the time for dissolution.

\section{Assessment of sperm penetration in vitro}

Frozen ejaculated spermatozoa (three pellets having a $200-\mu$ l volume and containing about $4 \times$ $10^{6}$ spermatozoa/pellet) were thawed in $2 \mathrm{ml}$ of PBS containing $0.1 \%(\mathrm{w} / \mathrm{v})$ BSA (A-8022; Fraction $\mathrm{V}$, Sigma), $100 \mu \mathrm{g} / \mathrm{ml}$ potassium penicillin $\mathrm{G}$ and 75 $\mu \mathrm{g} / \mathrm{ml}$ streptomycin sulphate at $37 \mathrm{C}$. After thawing, $8-10 \mathrm{ml}$ of the same medium was added and the spermatozoa were then washed twice by centrifugation, each time at $550 \times \mathrm{g}$ for $4 \mathrm{~min}$. After washing, the sperm pellet was resuspended to give various concentrations $\left(1-10 \times 10^{6}\right.$ cells $\left./ \mathrm{ml}\right)$ of spermatozoa according to the different experiments with IVF medium. The sperm suspension $(50 \mu \mathrm{l})$ was introduced into $50 \mu 1$ of IVF medium containing 10-15 denuded oocytes and covered with paraffin oil in a polystyrene culture dish $(35 \times$ $10 \mathrm{~mm}$ ). At $12 \mathrm{~h}$ after the start of culture at $39 \mathrm{C}$ in $5 \% \mathrm{CO}_{2}$ in air, oocytes were fixed, stained and examined for sperm penetration under a phasecontrast microscope at magnifications of $\times 200$ and $\times 400$. Oocytes were considered penetrated when 
they had one or more morphologically changed sperm nucleus and corresponding sperm tail(s).

\section{Statistical analysis}

All data obtained from four to six replicates were analyzed using one-way ANOVA. Proportional data were subjected to arc-sin transformation and the transformed values were used for the analyses. When ANOVA revealed a significant treatment effect, multiple comparisons and comparisons between two treatments were made by Fisher's protected least significant difference and Student's $t$-test, respectively, using the STATVIEW IV program (Abacus Concepts, Inc., Berkeley, CA, USA).

\section{Results}

\section{Activation and early development of CaA treated oocytes}

As shown in Fig. 1, no oocytes were activated when they were not treated with $\mathrm{CaA}$. However, when treated with $6.25 \mu \mathrm{M} \mathrm{CaA}$, a high proportion $(87.6 \pm 2.3 \%)$ of oocytes was activated. Although a similar activation rate was obtained in oocytes treated with $12.5 \mu \mathrm{M} \mathrm{CaA}(82.7 \pm 4.0 \%)$, the rates were significantly $(\mathrm{P}<0.05)$ reduced when the concentration of $\mathrm{CaA}$ was increased to 25 (68.6 \pm $7.6 \%)$ and $50 \mu \mathrm{M}(41.7 \pm 7.6 \%)$. As shown in Fig. 2, when oocytes were cultured after treatment with $\mathrm{CaA}$, the proportion of oocytes cleaved at $48 \mathrm{~h}$ of culture was significantly $(\mathrm{P}<0.05)$ reduced in a concentration-dependent manner. At $168 \mathrm{~h}$ of culture, the proportion of blastocyst formation was not different between oocytes treated with 6.25 $(19.8 \pm 6.6 \%)$ and $12.5(18.5 \pm 6.9 \%) \mu \mathrm{M} \mathrm{CaA}$, but it was significantly $(\mathrm{P}<0.05)$ reduced in oocytes treated with $25(2.8 \pm 2.0 \%)$ and $50(3.0 \pm 2.1 \%) \mu \mathrm{M}$ CaA.

\section{Penetration in vitro and solubility of the $\mathrm{ZP}$ of $\mathrm{CaA}$ treated oocytes}

A high proportion $(70.4 \pm 3.7 \%)$ of oocytes that were not treated with $\mathrm{CaA}$ were penetrated in vitro when they were inseminated with a fixed concentration $\left(1 \times 10^{6}\right.$ cells $\left./ \mathrm{ml}\right)$ of spermatozoa (Fig. 3A). This value was similar to that $(62.7 \pm$ $6.2 \%$ ) in oocytes treated with $6.25 \mu \mathrm{M} \mathrm{CaA}$. However, penetration rates in oocytes treated with $12.5(49.8 \pm 6.0 \%)$ and $50(24.6 \pm 5.2 \%) \mu \mathrm{M} \mathrm{CaA}$ were

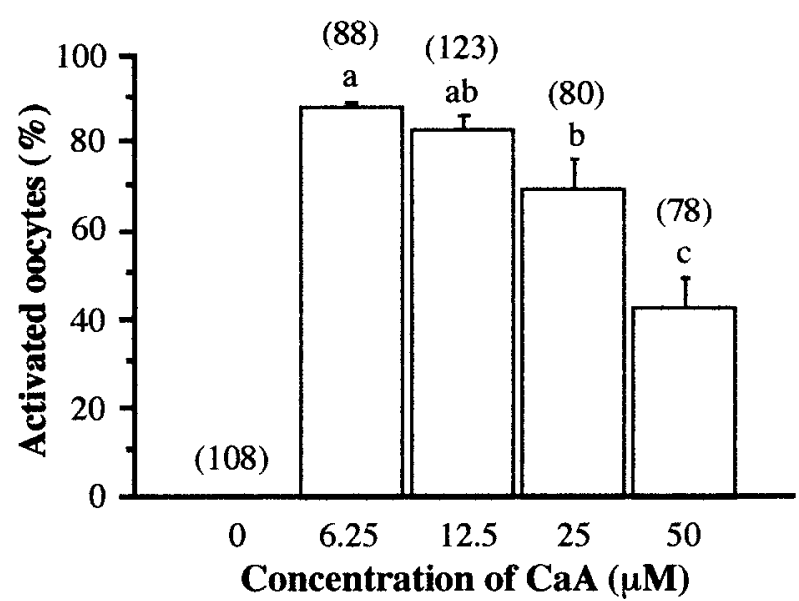

Fig. 1. Activation of pig oocytes matured in vitro, treated with various concentrations of Ca-ionophore A23187 (CaA) for $2 \mathrm{~min}$ in IVF medium, and cultured for $12 \mathrm{~h}$ in the same medium. Values obtained from four replicates are expressed as mean \pm SEM. The numbers of oocytes examined are indicated in parentheses. Values with different letters differ significantly $(\mathrm{P}<0.05)$.

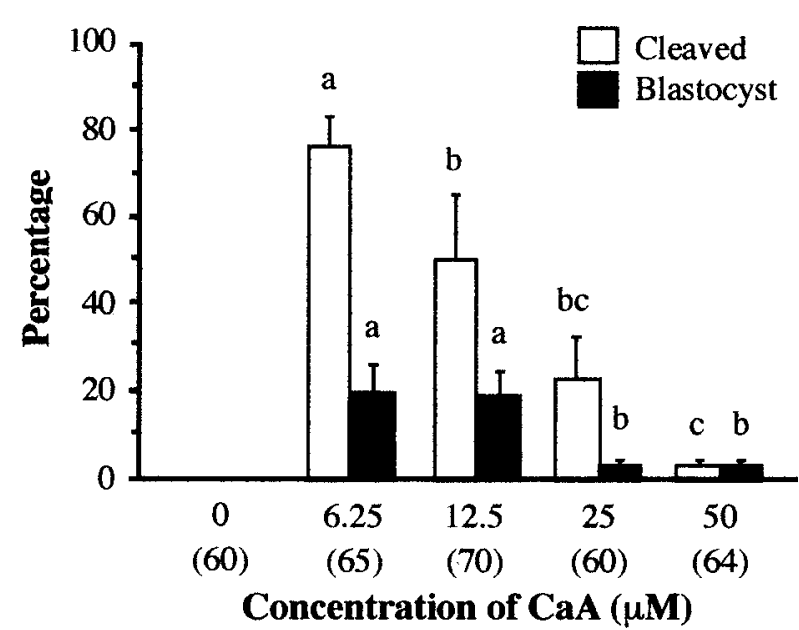

Fig. 2. Early development of pig oocytes matured in vitro and treated with various concentrations of $\mathrm{Ca}$ ionophore A23187 (CaA) for 2 min in IVF medium. The treated oocytes were cultured for $6 \mathrm{~h}$ in IVF medium supplemented with $2.5 \mu \mathrm{g} / \mathrm{ml}$ cytochalasin $\mathrm{B}(\mathrm{CB})$ and for a further $6 \mathrm{~h}$ in the medium without CB. Then the oocytes were transferred into NCSU 23 medium and cultured for their development. The oocytes cleaved to the 2- to 4-cell stages and developed to blastocysts were observed 48 and 168 $\mathrm{h}$ after the start of culture, respectively. Values obtained from four replicates are expressed as mean \pm SEM. The numbers of oocytes examined are indicated in parentheses. Values with different letters within each category of the development differ significantly $(\mathrm{P}<0.05)$. 


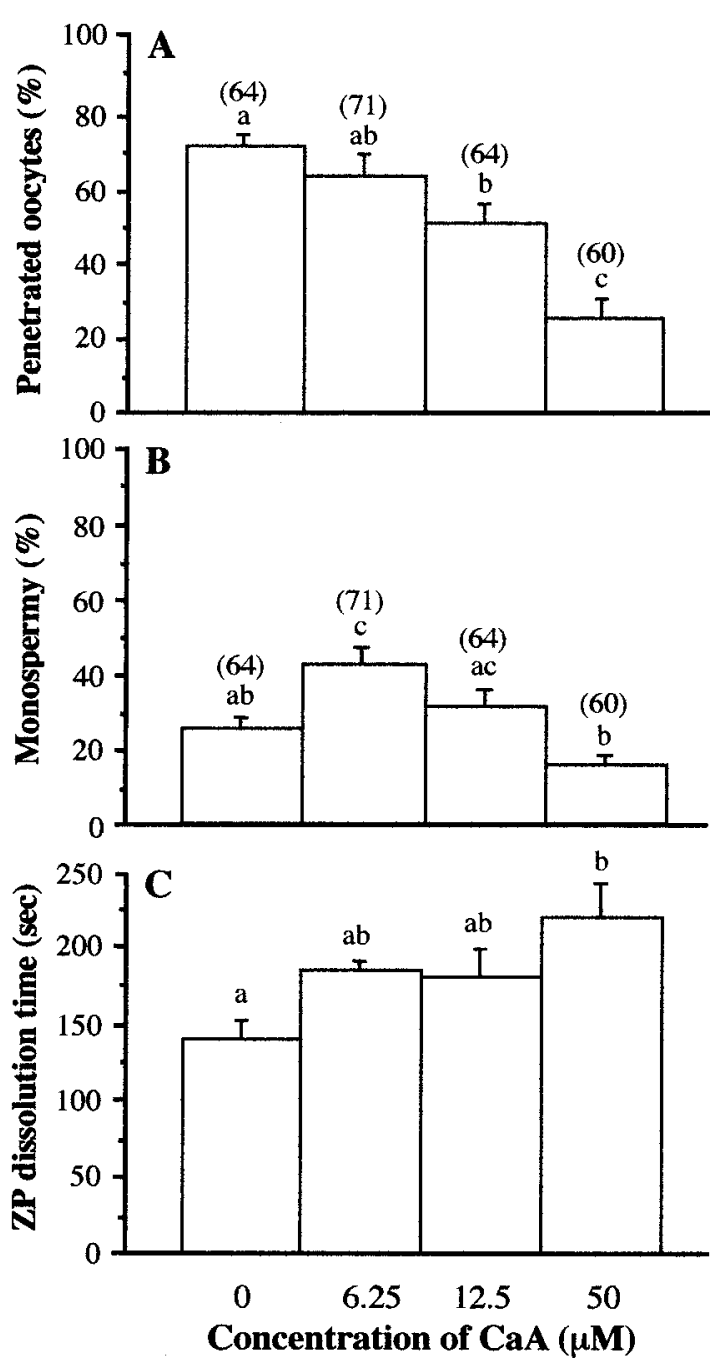

Fig. 3. Penetration in vitro and solubility of the zona pellucida (ZP) of pig oocytes treated with various concentrations of Ca-ionophore A23817 $(\mathrm{CaA})$ for $2 \mathrm{~min}$. Oocytes inseminated with frozen-thawed boar spermatozoa at a concentration of $1 \times 10^{6}$ cells $/ \mathrm{ml}$ were examined $12 \mathrm{~h}$ after insemination for penetration (A) and monospermy (B). Values obtained from six replicates are expressed as percentage (mean \pm SEM) of inseminated oocytes. The numbers of oocytes inseminated are indicated in parentheses. For assessment of solubility of the $\mathrm{ZP}$, oocytes treated with $\mathrm{CaA}$ were cultured for $4.5 \mathrm{~h}$ in IVF medium and then 8 or 10 oocytes were introduced into modified HEPES-buffered Tyrode's medium containing $0.1 \%(\mathrm{w} / \mathrm{v})$ polyvinylalcohol and $0.1 \%(\mathrm{w} / \mathrm{v})$ protease. The time required for dissolution of the $\mathrm{ZP}$ in half the number of oocytes was designated as the time for dissolution (C). Values obtained from four replicates are expressed as mean \pm SEM. Values with different letters in each measurement differ significantly $(\mathrm{P}<0.05)$.

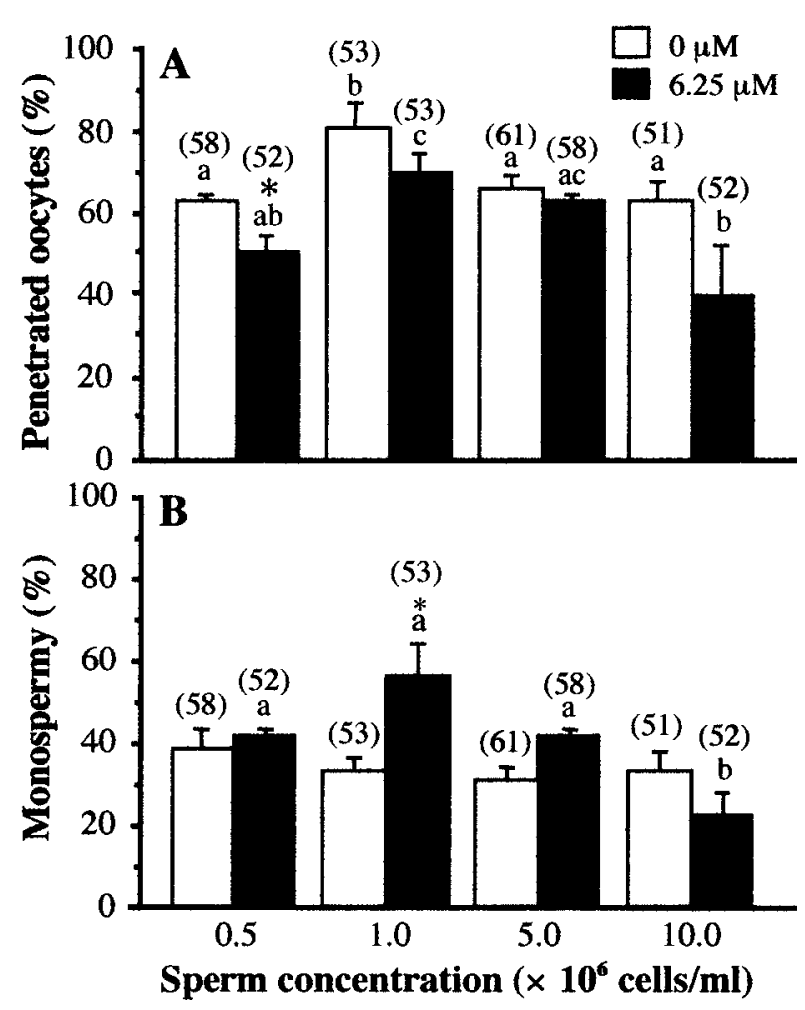

Fig. 4. Total penetration (A) and monospermic penetration (B) in vitro of pig oocytes treated $(6.25 \mu \mathrm{M})$ or not treated $(0 \mu \mathrm{M})$ with Ca-ionophore A23187 (CaA) and inseminated with various concentrations of spermatozoa. Values obtained from five replicates are expressed as \% (mean \pm SEM) of inseminated oocytes. The numbers of oocytes inseminated are indicated in parentheses. Values with different letters within each concentration of $\mathrm{CaA}$ differ significantly $(\mathrm{P}<0.05)$. Values with an asterisk differ significantly from that in untreated oocytes within the same sperm concentration $(\mathrm{P}<0.05)$.

significantly $(\mathrm{P}<0.05)$ lower than untreated oocytes. On the other hand, the proportion of monospermic penetration in oocytes treated with $6.25 \mu \mathrm{M} \mathrm{CaA}$ $(41.5 \pm 4.5 \%)$ was not significantly different to that $(30.1 \pm 4.6 \%)$ in oocytes treated with $12.5 \mu \mathrm{M} \mathrm{CaA}$, but it was significantly $(\mathrm{P}<0.05)$ higher than the values in oocytes not treated $(23.8 \pm 3.4 \%)$ or treated with $50 \mu \mathrm{M} \mathrm{CaA}(14.9 \pm 2.0 \%)$ (Fig. 3B). When oocytes were treated with $0.1 \%$ protease after treatment with $\mathrm{CaA}$, the time required for dissolution of the ZP was not different among oocytes treated with $6.25-50 \mu \mathrm{M} \mathrm{CaA}(175.0 \pm 18.7-$ $215.5 \pm 21.6 \mathrm{sec}$ ) (Fig. 3C). However, oocytes treated with $50 \mu \mathrm{M}$ CaA required a significantly (P $<0.05)$ longer time $(215.5 \pm 21.6 \mathrm{sec})$ than that $(136.3$ $\pm 13.3 \mathrm{sec})$ in untreated oocytes for dissolution of 
the ZP.

Penetration in vitro of oocytes treated with $6.25 \mu \mathrm{M}$ $\mathrm{CaA}$ and inseminated with various concentrations of spermatozoa

The penetration rate $(80.5 \pm 6.5 \%)$ of untreated oocytes was significantly $(\mathrm{P}<0.05)$ higher when they were inseminated with $1.0 \times 10^{6}$ spermatozoa/ $\mathrm{ml}$ than $0.5,5.0$ or $10.0 \times 10^{6}$ spermatozoa $/ \mathrm{ml}(62.2$ $\pm 2.0-65.8 \pm 4.0 \%$ ) (Fig. 4 A). A similar result was obtained in oocytes treated with $6.25 \mu \mathrm{M} \mathrm{CaA}$, but there was no significant difference in penetration rates between oocytes inseminated with $1.0(70.2 \pm$ $4.3 \%)$ and $5.0(62.4 \pm 2.4 \%) \times 10^{6}$ spermatozoa $/ \mathrm{ml}$. Although a significantly $(\mathrm{P}<0.05)$ higher proportion of untreated oocytes was penetrated than treated oocytes when inseminated with $0.5 \times 10^{6}$ spermatozoa/ml, there was no difference in penetration rates with the other sperm concentrations. There was no significant difference in the proportions of monospermic penetration when different concentrations of spermatozoa were used for insemination in untreated oocytes (29.5 $\pm 3.9-37.8 \pm 4.9 \%$ ) (Fig. 4B). However, in treated oocytes, significantly $(\mathrm{P}<0.05)$ higher proportions of monospermic penetration were obtained using $0.5-5.0(40.6 \pm 2.5-54.6 \pm 8.8 \%)$ than $10.0(21.6 \pm$ $5.4 \%) \times 10^{6}$ spermatozoa $/ \mathrm{ml}$. At a sperm concentration of $1.0 \times 10^{6}$ cells $/ \mathrm{ml}$, a significantly $(\mathrm{P}<0.05)$ higher proportion of monospermy was observed in treated $(54.6 \pm 8.8 \%)$ than in untreated $(31.9 \pm 3.4 \%)$ oocytes.

\section{Discussion}

It has been reported that activation of pig oocytes is not induced properly by treatment with $30-50$ $\mu \mathrm{M} \mathrm{CaA}$ for 30-60 min in medium with FBS $[32,36]$. However, in medium without FBS and with a higher concentration $(7.5 \mathrm{mM})$ of calcium, treatment with $\mathrm{CaA}$ for only $5 \mathrm{~min}$ activated oocytes in a concentration-dependent manner [27]. At a fixed concentration $(50 \mu \mathrm{M})$ of $\mathrm{CaA}$, more oocytes were activated when treated for $2 \mathrm{~min}$ than 0.5 and $1 \mathrm{~min}$ in the same medium, although there was no difference in activation rates between oocytes treated for 2 and $5 \mathrm{~min}$ [31]. In the present study, when oocytes were treated with CaA for 2 min in medium with a lower concentration (3.26 $\mathrm{mM}$ ) of calcium, the proportions of oocytes activated were reduced as the concentration of $\mathrm{CaA}$ increased from 6.25 to $50 \mu \mathrm{M}$. This contrasts with the observation of Wang et al. [27] and may be due to the different concentrations of calcium in the medium used. In the study of Wang et al. [31], many of the pig oocytes treated with $50 \mu \mathrm{M} \mathrm{CaA}$ for 5 min in medium without calcium formed condensed chromatin and no microtubules were observed in these oocytes. These have been reported to reduce activation rates [31] and therefore a detrimental effect of CaA may occur in a concentration-dependent manner, such as when the oocytes are treated with $\mathrm{CaA}$ in medium containing a lower concentration of calcium.

It has been reported in mice that diploid embryos possess higher developmental ability than haploid embryos [37]. In pigs, electrically activated oocytes showed a higher incidence of diploid formation than CaA-activated oocytes and the former showed higher rates of blastocyst formation than the latter [38]. Therefore, in the present study, to study developmental competence of oocytes treated with $\mathrm{CaA}$, the treated oocytes were first cultured for $6 \mathrm{~h}$ in IVF medium containing CB and further for $6 \mathrm{~h}$ in the same medium without $C B$ to induce diploid formation. When oocytes were cultured in NCSU23 medium for $36 \mathrm{~h}$ after the two-step culture, the cleavage rate was reduced as the concentration of $\mathrm{CaA}$ increased from 6.25 to $50 \mu \mathrm{M}$. After a longer period (156 h) of culture, the proportion of oocytes that developed to blastocysts was also lower in those treated with 25 and $50 \mu \mathrm{M}$ than 6.25 and 12.5 $\mu \mathrm{M} \mathrm{CaA}$. This may be due to the lower activation rate in oocytes treated with higher concentrations of $\mathrm{CaA}$ under the present experimental conditions, in which we examined activation rate of oocytes treated only with $\mathrm{CaA}$, but not with $\mathrm{CaA}+\mathrm{CB}$. It has been reported that the amplitude of the intracellular calcium transients in pig oocytes treated with CaA increased in a concentrationdependent manner [27]. Although an increase of intracellular calcium is important for initiation of activation and development of oocytes, the present results show that treatment with increased concentrations of $\mathrm{CaA}$ does not necessarily stimulate activation and development of oocytes. Since activation rate and developmental ability are higher in pig oocytes treated with two electric pulses inducing two calcium transients than $\mathrm{CaA}$ [27], this suggests that the number of calcium transients may be more important than the 
intracellular calcium increase for inducing activation and development of pig oocytes.

The $\left[\mathrm{Ca}^{2+}\right] \mathrm{i}$ increase in pig oocytes treated with $\mathrm{CaA}$ is responsible for a zona reaction in which zona hardening occurs [27]. In the present study, the time requirement for dissolution of $\mathrm{ZP}$ of pig oocytes treated with different concentrations of $\mathrm{CaA}$ was examined to assess the degree of zona hardening. The results obtained showed that the dissolution time was significantly increased in oocytes treated with $50 \mu \mathrm{M} \mathrm{CaA}$, but not in oocytes treated with 6.25 and $12.5 \mu \mathrm{M} \mathrm{CaA}$, compared with untreated oocytes, suggesting that zona hardening was not promoted by treatment with the lower concentrations of CaA to a level that could be detected in this study. Nevertheless, when inseminated with a fixed concentration $\left(1 \times 10^{6}\right.$ cells $/ \mathrm{ml}$ ) of spermatozoa, similar penetration rates were obtained between untreated oocytes and those treated with $6.25 \mu \mathrm{M} \mathrm{CaA}$. However, the penetration rates of oocytes treated with 12.5 to 50 $\mu \mathrm{M} \mathrm{CaA}$ were significantly reduced compared with untreated oocytes. These results suggest that zona solubility by protease does not necessarily reflect the penetrability of oocytes in vitro. The lack of a close correlation between zona solubility and penetrability of pig oocytes in vitro has also been suggested by Wang et al. [27].

One of the most interesting observations in the present study was that treatment of oocytes with $6.25 \mu \mathrm{M} \mathrm{CaA}$ for $2 \mathrm{~min}$ followed by insemination with $1.0 \times 10^{6}$ spermatozoa $/ \mathrm{ml}$ increased the incidence of monospermy without reducing the penetration rate compared with untreated oocytes. To our knowledge, our previous investigation [32] and the present study are the first to have found that polyspermic penetration in vitro can be regulated by treatment of pig oocytes with $\mathrm{CaA}$. In our previous study [32], treatment of pig oocytes with $5 \mu \mathrm{M} \mathrm{CaA}$ for longer periods (30-120 $\mathrm{min}$ ) in medium without FBS also increased the incidence of monospermy without reducing the penetration rate. In that study, cumulus-enclosed oocytes matured only for $33 \mathrm{~h}$ in culture were treated with $\mathrm{CaA}$ in IVM medium without BSA, while in the present study, oocytes freed from cumulus cells after full maturation for $44 \mathrm{~h}$ in culture were treated with CaA in IVF medium with BSA. Therefore, it is difficult to compare the results obtained in the present study with those obtained in the previous study. However, since oocytes that have reached metaphase II develop full ability to induce CG exocytosis in all animals examined [39], including pigs [17], oocytes matured for $33 \mathrm{~h}$ may require a longer period of treatment with $\mathrm{CaA}$ to induce CG exocytosis and zona reaction than those matured fully for $44 \mathrm{~h}$. The mechanism regulating polyspermic penetration in pig oocytes treated with $\mathrm{CaA}$ was unclear in the previous $[17,32]$ and the present studies. A possible explanation is that a lower and incomplete CG exocytosis in pig oocytes penetrated in vitro [14] may be modified by the treatment of oocytes with $\mathrm{CaA}$ before insemination. It has been reported that most CGs are released equally from both oocytes matured in vivo and in vitro, providing evidence that both CG exocytosis itself and the events after exocytosis must play important role(s) in establishing a functional block to polyspermy [40]. Therefore, it seems likely that moderately induced CG exocytosis in oocytes treated with appropriate concentrations of $\mathrm{CaA}$ is compensated for by sperm penetration and the subsequent reaction of the CG contents with the $\mathrm{ZP}$ is enhanced to regulate continuous sperm penetration in vitro.

In the present study, penetration rates of oocytes both not treated and treated with $6.25 \mu \mathrm{M} \mathrm{CaA}$, were significantly increased when inseminated with 1.0 rather than $0.5 \times 10^{6}$ spermatozoa $/ \mathrm{ml}$, but these rates gradually reduced as the sperm concentration increased up to $10.0 \times 10^{6}$ cells $/ \mathrm{ml}$. Although there were no differences in the proportions of monospermy between untreated and treated oocytes inseminated with 0.5, 5.0 and $10.0 \times 10^{6}$ spermatozoa $/ \mathrm{ml}$, a significantly higher proportion of monospermy was observed in treated than untreated oocytes inseminated with $1.0 \times 10^{6}$ spermatozoa $/ \mathrm{ml}$. These results indicate that the sperm concentration used for insemination in vitro is also an important factor in the increased proportion of monospermy in $\mathrm{CaA}$ treated oocytes.

In conclusion, the results of the present study indicate that the treatment of pig oocytes in vitro with $6.25 \mu \mathrm{M} \mathrm{CaA}$ for $2 \mathrm{~min}$ is effective for inducing activation, cleavage and blastocyst formation. This treatment also increases the incidence of monospermy without reducing penetration rates, when oocytes are inseminated with a concentration of $1.0 \times 10^{6} \mathrm{spermatozoa} / \mathrm{ml}$. 


\section{Acknowledgements}

We thank Professor Morag G. Hunter, University of Nottingham, for critical reading and valuable suggestions for the manuscript. This work was partly supported by a grant from Takeda Chemical Industries, Ltd., Osaka, Japan and by a Grant-inAid for Creative Scientific Research from the Japan Society for the Promotion of Science (13GS0008).

\section{References}

1. Jeffe LF. The role of calcium explosions, waves and pulses in activating eggs. In: Metz CB, Monroy A (eds), Biology of Fertilization: Academic Press, New York; 1985: 127-165.

2. Miyazaki $S$, Hashimoto $N$, Yoshimoto $Y$, Kishimoto T, Igusa Y, Hiramoto $\mathbf{Y}$. Temporal and spatial dynamics of the periodic increase in intracellular free calsium at fertilization of golden hamster eggs. Dev Biol 1986; 118: 259-267.

3. Kline D, Kline J. Repetitive calcium transients and the role of calcium in exocytosis and cell cycle activation in the mouse egg. Dev Biol 1992; 149: 8089.

4. Fissore RA, Dobrinsky JR, Balise JJ, Duby RT, Robl JM. Patterns of intracellular $\mathrm{Ca}^{2+}$ concentrations in fertilized bovine eggs. Biol Reprod 1992; 47: 960-969.

5. Sun FZ, Hoyland J, Huang X, Mason W, Moor RM. A comparison of intracellular changes in porcine eggs after fertilization and electroactivation. Development 1992; 115: 947-956.

6. Machaty Z, Funahashi H, Day BN, Prather RS. Developmental changes in the intracellular $\mathrm{Ca}^{2+}$ release mechanisms in porcine oocytes. Biol Reprod 1997; 56: 921-930.

7. Schmell ED, Gulyas BJ, Hedrick JL. Egg surface changes during fertilization and the molecular mechanism of the block to polyspermy. In: Hartmann JF (ed.), Mechanism and Control of Animal Fertilization. Academic Press, New York; 1983: 365-413.

8. Hoodbhoy $\mathrm{T}$, Talbot P. Mammalian cortical granules: contents, fate and function. Mol Reprod Dev 1994; 39: 439-448.

9. Yanagimachi R. Mammalian fertilization. In: Knobil E, Neill JD (eds), The Physiology of Reproduction. 2nd ed, Raven Press, Ltd., New York; 1994: 189-317.

10. Hunter RHF. Oviduct function in pigs, with particular reference to the pathological condition of polyspermy. Mol Reprod Dev 1991; 29: 385-391.

11. Niwa K. Effectiveness of in vitro maturation and in vitro fertilization techniques in pigs. J Reprod Fertil, Suppl 1993; 48: 49-59.

12. Nagai T. In vitro maturation and fertilization of pig oocytes. Anim Reprod Sci 1996; 42: 153-163.

13. Funahashi $\mathbf{H}$, Day $\mathbf{B N}$. Advances in in vitro production of porcine embryos. J Reprod Fertil, Suppl
1997; 52: 271-283.

14. Cran DG, Cheng WTK. The cortical reaction in pig oocytes during in vivo and in vitro fertilization. Gamete Res 1986; 13: 241-251.

15. Yoshida M, Cran DG, Pursel VG. Confocal and fluorescence microscopic study using lectins of the distribution of cortical granules during the maturation and fertilization of pig oocytes. $\mathrm{Mol}$ Reprod Dev 1993; 36: 462-468.

16. Kim NH, Funahashi H, Abeydeera LR, Moon SJ, Prather RS, Day BN. Effects of oviductal fluid on sperm penetration and cortical granule exocytosis during fertilization of pig oocytes in vitro. J Reprod Fertil 1996; 107: 79-86.

17. Wang WH, Hosoe $\mathbf{M}$, Shioya Y. Induction of cortical granule exocytosis of pig oocytes by spermatozoa during meiotic maturation. J Reprod Fertil 1997; 109: 247-255.

18. Wang WH, Machaty Z, Abeydeera LR, Prather RS, Day BN. Time course of cortical and zona reactions of pig oocytes upon intracellular calcium increase induced by thimerosal. Zygote 1999; 7: 79-86.

19. Hunter RHF. Modulation of gamete and embryonic microenvironments by oviduct glycoproteins. Mol Reprod Dev 1994; 39: 176-181.

20. McCauley TC, Buhi WC, Wu GM, Mao J, Caamaño JN, Didion BA, Day BN. Oviduct-specific Glycoprotein modulates sperm-zona binding and improves efficiency of porcine fertilization in vitro. Biol Reprod 2003; 69: 828-834.

21. Nagai T, Moor RM. Effect of oviduct cells on the incidence of polyspermy in pig eggs fertilized in vitro. Mol Reprod Dev 1990; 26: 377-382.

22. Kano K, Miyano T, Kato S. Effect of oviductal epithelial cells on fertilization of pig oocytes in vitro. Theriogenology 1994; 42: 1061-1068.

23. Suzuki K, Eriksson B, Shimizu H, Nagai T, Rodriguez-Martinez $\mathbf{H}$. Effect of hyaluronan on monospermic penetration of porcine oocytes fertilized in vitro. Int J Androl 2000; 23: 13-21.

24. Funahashi H, Fujiwara T, Nagai T. Modulation of function of boar spermatozoa via adenosine and fertilization promoting peptide receptors reduce the incidence of polyspermic penetration into porcine oocytes. Biol Reprod 2000; 63: 1157-1163.

25. Tawia SA, Lopata A. The fertilization and development of mouse oocytes following cortical 
granule discharge in the presence of a protease inhibitor. Hum Reprod 1992; 7: 1004-1009.

26. Zhang X, Rutledge J, Khamsi F, Armstrong DT. Release of tissue-type plasminogen activator by activated rat eggs and its possible role in the zona reaction. Mol Reprod Dev 1992; 32: 28-32.

27. Wang WH, Machaty Z, Abeydeera LR, Prather RS, Day BN. Parthenogenetic activation of pig oocytes with calcium ionophore and the block to sperm penetration after activation. Biol Reprod 1998; 58: 1357-1366.

28. Steinhardt RA, Epel D. Activation of sea-urchin eggs by a calcium ionophore. Proc Natl Acad Sci USA 1974; 71: 1915-1919.

29. Shiina Y, Kaneda M, Matsuyama K, Tanaka K, Hiroi M, Doi K. Role of the extracellular $\mathrm{Ca}^{2+}$ on the intracellular $\mathrm{Ca}^{2+}$ changes in fertilized and activated mouse oocytes. J Reprod Fertil 1993; 97: 143-150.

30. Hagen DR, Prather RS, First NL. Response of porcine oocytes to electrical and chemical activation during maturation in vitro. Mol Reprod Dev 1991; 28: 70-73.

31. Wang WH, Machaty Z, Ruddock N, Abeydeera LR, Boquest AC, Prather RS, Day BN. Activation of porcine oocytes with calcium ionophore: effects of extracellular calcium. Mol Reprod Dev 1999; 53: 99107.

32. Song X-X, Zhao X-M, Han Y-B, Niwa K. Effect of treatment of in vitro matured pig oocytes with calcium ionophore on monospermic penetration in vitro. Asian-Aust J Anim Sci 2001; 15: 172-178.
33. Naito K, Fukuda Y, Toyoda Y. Effects of porcine follicular fluid on male pronucleus formation in porcine oocytes matured in vitro. Gamete Res 1988; 21: 289-295.

34. Wang WH, Niwa K, Okuda K. In-vitro penetration of pig oocytes matured in culture by frozen-thawed ejaculated spermatozoa. J Reprod Fertil 1991; 93: 491496.

35. Petters RM, Wells KD. Culture of pig embryos. J Reprod Fertil, Suppl 1993; 48: 61-73.

36. Wang WH, Sun QY, Hosoe M, Shioya Y, Day BN. Quantified analysis of cortical granule distribution and exocytosis of porcine oocytes during meiotic maturation and activation. Biol Reprod 1997; 56: 1376-1382.

37. Kaufman MH, Sachs L. Complete preimplantation development in culture of parthenogenetic mouse embryos. J Embryol Exp Morphol 1976; 35: 179-190.

38. Wang WH, Abeydeera LR, Prather RS, Day BN. Functional analysis of activation of porcine oocytes by spermatozoa, calcium ionophore, and electrical pulse. Mol Reprod Dev 1998; 51: 346-353.

39. Ducibella T. The cortical reaction and development of activation competence in mammalian oocytes. Hum Reprod Update 1996; 2: 29-42.

40. Wang WH, Abeydeera LR, Prather RS, Day BN. Morphologic comparison of ovulated and in vitromatured porcine oocytes, with particular reference to polyspermy after in vitro fertilization. Mol Reprod Dev 1998; 49: 308-316. 